\title{
Functional analysis of GhCHS, GhANR and GhLAR in colored fiber formation of Gossypium hirsutum L
}

\author{
Jianfang Gao ${ }^{1 \dagger}$, Li Shen ${ }^{1 \dagger}$, Jingli Yuan ${ }^{1}$, Hongli Zheng ${ }^{1}$, Quansheng Su', Weiguang Yang ${ }^{1}$, Liqing Zhang ${ }^{1}$,
} Vitalis Ekene Nnaemeka', Jie Sun'², Liping Ke ${ }^{1 *}$ and Yuqiang Sun ${ }^{*^{*}}$ (D)

\begin{abstract}
Background: The formation of natural colored fibers mainly results from the accumulation of different anthocyanidins and their derivatives in the fibers of Gossypium hirsutum L. Chalcone synthase (CHS) is the first committed enzyme of flavonoid biosynthesis, and anthocyanidins are transported into fiber cells after biosynthesis mainly by Anthocyanidin reductase (ANR) and Leucoanthocyanidin reductase (LAR) to present diverse colors with distinct stability. The biochemical and molecular mechanism of pigment formation in natural colored cotton fiber is not clear.

Results: The three key genes of GhCHS, GhANR and GhLAR were predominantly expressed in the developing fibers of colored cotton. In the GhCHSi, GhANRi and GhLARi transgenic cottons, the expression levels of GhCHS, GhANR and GhLAR significantly decreased in the developing cotton fiber, negatively correlated with the content of anthocyanidins and the color depth of cotton fiber. In colored cotton Zongxu1 (ZX1) and the GhCHSi, GhANRi and GhLARi transgenic lines of ZX1, $\mathrm{HZ}$ and $\mathrm{ZH}$, the anthocyanidin contents of the leaves, cotton kernels, the mixture of fiber and seedcoat were all changed and positively correlated with the fiber color.

Conclusion: The three genes of GhCHS, GhANR and GhLAR were predominantly expressed early in developing colored cotton fibers and identified to be a key genes of cotton fiber color formation. The expression levels of the three genes affected the anthocyanidin contents and fiber color depth. So the three genes played a crucial part in cotton fiber color formation and has important significant to improve natural colored cotton quality and create new colored cotton germplasm resources by genetic engineering.
\end{abstract}

Keywords: G. hirsutum L., Fiber color, Anthocyanidin, GhCHS, GhANR, GhLAR

\section{Background}

Cotton, as one of the most important economic crops, provides more than $50 \%$ of the fiber source in the textile industry [1]. However, the printing and dyeing processes contain many carcinogens, resulted in bleaching difficulties, containing high concentrations of halides organic matter, most organic halides are carcinogenic, teratogenic and mutagenic [2-6] are also typical persistent

\footnotetext{
* Correspondence: keliping@zstu.edu.cn; sunyuqiang@zstu.edu.cn

${ }^{\dagger}$ Jianfang Gao and Li Shen contributed equally to this work.

'Plant Genomics \& Molecular Improvement of Colored Fiber Lab, Key

Laboratory of Plant Secondary Metabolism and Regulation of Zhejiang

Province, College of Life Sciences and Medicine, Zhejiang Sci-Tech University,

Hangzhou 310016, Zhejiang, China

Full list of author information is available at the end of the article
}

organic pollutants $[7,8]$, which are very difficult to recover. Fortunately, the natural colored cotton fibers yarn without or very less dyeing directly into cloth and show great application prospects in the textile industry. Because of the green, ecological and eco-friendly characteristics, the natural colored cotton and its fabrics are praised as " $21^{\text {st }}$ century Darling", and also undoubtedly becoming an important choice and way for the transformation and upgrading of the textile industry in China. But currently only two types of colored cotton with brown and green color are available in the actual production and textile industry, which seriously restricts the development of colored cotton industry [8-15]. Natural colored cotton fibers were pigmented by synthesizing

(c) The Author(s). 2019 Open Access This article is distributed under the terms of the Creative Commons Attribution 4.0 International License (http://creativecommons.org/licenses/by/4.0/), which permits unrestricted use, distribution, and 
and accumulating natural pigments in developing fiber, the previous reports showed the brown coloration of cotton fibers resulted from flavonoids synthesis and accumulation in fibers $[3,16]$, proanthocaynidins (PAs) biosynthesis and accumulation played the leading role for the brown coloration in cotton fibers [10, 11, 17-21]. Because of the complex pigment composition and structure in colored cotton fibers, it is difficult to genetically improve cotton fiber color, and the mechanism of pigment formation in the colored fiber is still unclear.

Flavonoids are one of the largest groups of secondary metabolites and widely distributed in plants ranging from spermatophytes to mosses [22-24]. The main classes of these phenylpropanoid pathway derivatives include flavonols, anthocyanins, and PAs. As water-soluble natural pigments, anthocyanins are responsible for the red, purple and blue colors of many flowers and fruit that attract pollinators and seed dispersers [25]. Over 600 anthocyanins have been identified in nature, the most common anthocyanins are pelargonidin, cyanidin, delphinidin, peonidin, petunidin, malvidin, and the derivatives of six widespread anthocyanidins, which constitute the dominant core anthocyanins in higher plants and exhibit different colors such as orange, red, purple, and blue in plant flowers, seeds, and fruits [26-29]. Plant flowers and fruits have a variety of colors because they are closely related to anthocyanins. The PAs play an important role in regulating many biological stresses and abiotic stresses in plant, and play a crucial part in the physiological processes such as anti-ultraviolet, disease resistance, scavenging free radicals, regulating seed dormancy and germination [29-34]. The anthocyanin biosynthetic pathway is an important branch of the general flavonoid pathway, the chalcone synthase $(\mathrm{CHS})$ is the first key regulatory enzyme which mediated synthesis of naringenin chalcone from 4-coumaroyl-CoA and malonyl-CoA. After biosynthesis, flavonoids are transported to vacuoles or cell walls [35]. The last steps of monomer biosynthesis are catalyzed by two distinct enzymes of leucoanthocyanidin reductase (LAR) and anthocyanidin reductase (ANR). LAR directly reduced leucoanthocyanidins to the corresponding 2, 3-trans-(6)flavan-3-ols such as catechin as the first step in PA biosynthesis. The anthocyanidin synthase (ANS) converted leucoanthocyanidins into the 2, 3-cis-type anthocyanidins such as epicatechin, and then anthocyanidins were reduced by ANR to synthesis the corresponding 2, 3-cisflavan-3-ol [36]. The anthocyanin branch point enzyme UDP-glycose: flavonoid-3-O-glycosyltransferase (UF3GT) and the PA branch point enzyme ANR both utilize the unstable flavonoid precursor cyanidin as a substrate. LAR also converted 4b-(S-cysteinyl)-epicatechin into free epicatechin for regulating the length of PA polymers in Medicago truncatula [37]. Both LAR and ANR are NADPH/
NADH-dependent isoflavone-like reductases belonging to the reductase epimerase-dehydrogenase superfamily.

So engineering paler color has been achieved relatively easily by silencing structural genes in the anthocyanin biosynthetic pathway. Shifts in color from blue to red have been achieved by silencing Flavanone 3, 5Hydroxylase gene $\left(F 3^{\prime} 5^{\prime} H\right)$ [38]. Novel, red colored seeds of soybean have been produced by inhibiting the activity of ANR in the seed coat [39]. The significantly suppressed soybean ANR1 and ANR2 genes resulted in the red-brown grain phenotype, the effects of silencing ANR1 and ANR2 redirected metabolic flux from PA biosynthesis into the anthocyanin and flavonol-3-O-glucoside pathways. ANR removed anthocyanidins to supply epicatechin for proanthocyanidin synthesis. In the absence of ANR activity, red cyanidin-based anthocyanins accumulated in the seed coat. LAR and ANR are the key enzymes of anthocyanin transport and proanthocyanidin synthesis.

The PA branchpoint genes in soybean seed coat tissue were silenced as a novel methods for genetically improved pigmentation in plants. Many economical crops also accumulated PAs in the seed coats, ANR gene could be suppressed for genetically modified grain color in canola (Brassica napus L.), flax (Linum usitatissimum), and wheat (Triticum spp.) [40-42].

In this study, the three key genes for anthocyanidin biosynthesis and transport in natural colored cotton fiber were analyzed. The fiber color was altered with the decreased transcript level of three key genes, which resulted in the content of anthocyanidins change. It is very important to genetic manipulation GhCHS, GhANR and GhLAR in the anthocyanin metabolic pathway to improve the cotton fiber color, to satisfy the increasing great demand for green textile industry.

\section{Results \\ Identification and phylogenetic analysis of GhCHS, GhLAR and GhANR genes}

The differentially expressed genes were scanned from the transcriptome of brown cotton and its near isogene line [11]. From the differentially expressed genes, the genes in the anthocyanidin biosynthesis pathway including GhCHS, GhLAR and GhANR were selected for further analysis in the colored fiber in G. hirsutum. In G. hirsutum, 7 GhCHS genes and 6 GhCHS-like genes were scanned, 2 GhANR genes and 3 GhLAR genes were obtained (Fig. 1).

Multiple ChCHSs contained high amino acid homology, the homology of special motifs reached $100 \%$, the GhCHS genes kept highly conserved in G. hirsutum (Fig. 1a). The GhLAR genes and GhANR genes were also much conserved in G. hirsutum (Fig. 1b, c). The members in the GhCHS family except GhCHSL-2 had two domains and 


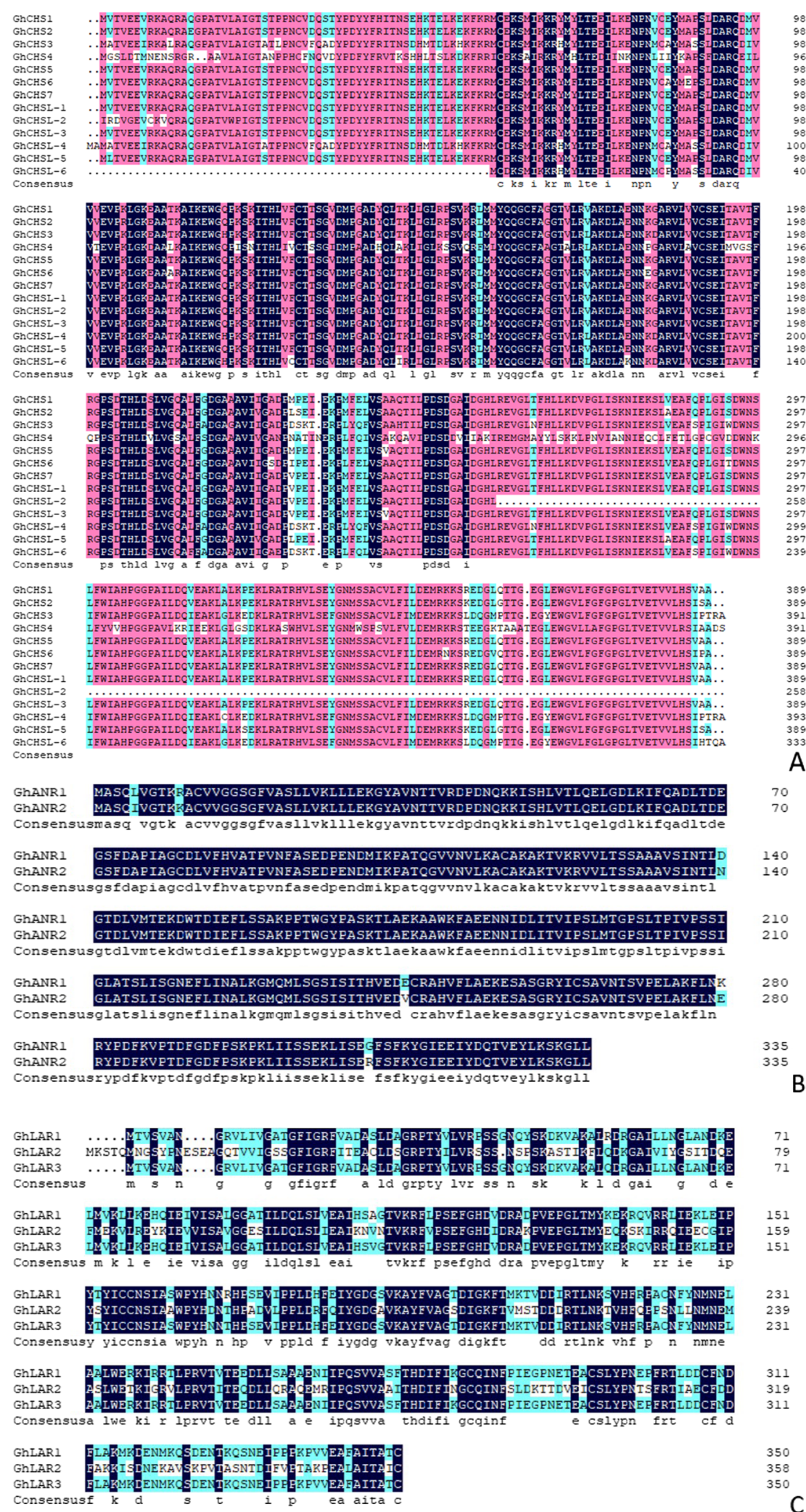

Fig. 1 Clustal W alignment of multiple amino acid sequences alignment of GhCHS, GhANR and GhLAR. Colors indicate the similarity of amino acids sequences coded by the GhCHS (a), GhANR (b), GhLAR (c) 
were mostly divided into $\mathrm{N}$-terminus and $\mathrm{C}$-terminus, but GhCHSL-2 has only N-terminal one (Fig. 2a). The GhANR1 and GhANR2 were also divided into N-terminal and C-terminal (Fig. 2b). GhLARs had only one Nterminal domain (Fig. 2c).

\section{Expression pattern of GhCHS, GhLAR and GhANR in the developing fibers}

The 7 GhCHS genes and 6 GhCHS-like genes, 2 GhANR genes and 3 GhLAR transcript levels in the developing fibers of different stages in the natural colored cotton Zongxu1 (ZX1) and different cotton species were measured. The 3 GhCHS genes (named GhCHS1, GhCHS2, and $G h C H S 3$ ) were detected in the developing fibers of ZX1, and GhCHS2 were predominant. The expression level of GhCHS2 was extremely higher than GhCHS1 and GhCHS3 and appeared most especially in the fiber of 5 and 10 DPA (days post anthesis) (Fig. 3a). The two GhANR genes (GhANR1 and GhANR2) were quantified in the developing fibers of ZX1, the maximal expression level appeared in the fiber of 10 DPA (Fig. 3b). The expression levels of GhANR genes were extremely higher than those of GhLAR genes to about 10-fold in the fibers of 5 DPA and 30 -fold in the fibers of 10 DPA. All
GhLAR genes were detected in the developing fibers from 0 DPA to 20 DPA, predominantly expressed in the developing fibers of 5 DPA and 10 DPA (Fig. 3c). From the expression pattern of GhCHS, GhLAR and GhANR, the 3 genes were all predominantly expressed in the fibers of $10 \mathrm{DPA}$, the gene expression patterns were further detected in different cotton species with different colored fibers at 10 DPA.

The 5 cotton species (with white fiber or brown fiber) were used to measure GhCHS, GhLAR and GhANR expression levels in the developing fibers of 10 DPA. In plant, chalcone synthase (CHS) gene is the first committed step of flavonoid biosynthesis, the expression levels of GhCHS genes were significantly higher in the colored fibers than in the white fibers, especially in ZX1 and HZ fibers of 10 DPA (Fig. 4a). For the GhCHS genes, GhCHS2 kept preferential expression and maintained the trend during the colored fiber development, GhCHS1 was weakly expressed and the expression level of GhCHS3 was almost negligible, so the GhCHS2 was measured to represent the transcript levels of GhCHS genes in the developing fibers, and the conserved sequence was used to interfere their transcripts. The expression levels GhANR genes in colored cotton HZ lines with dark brown fiber

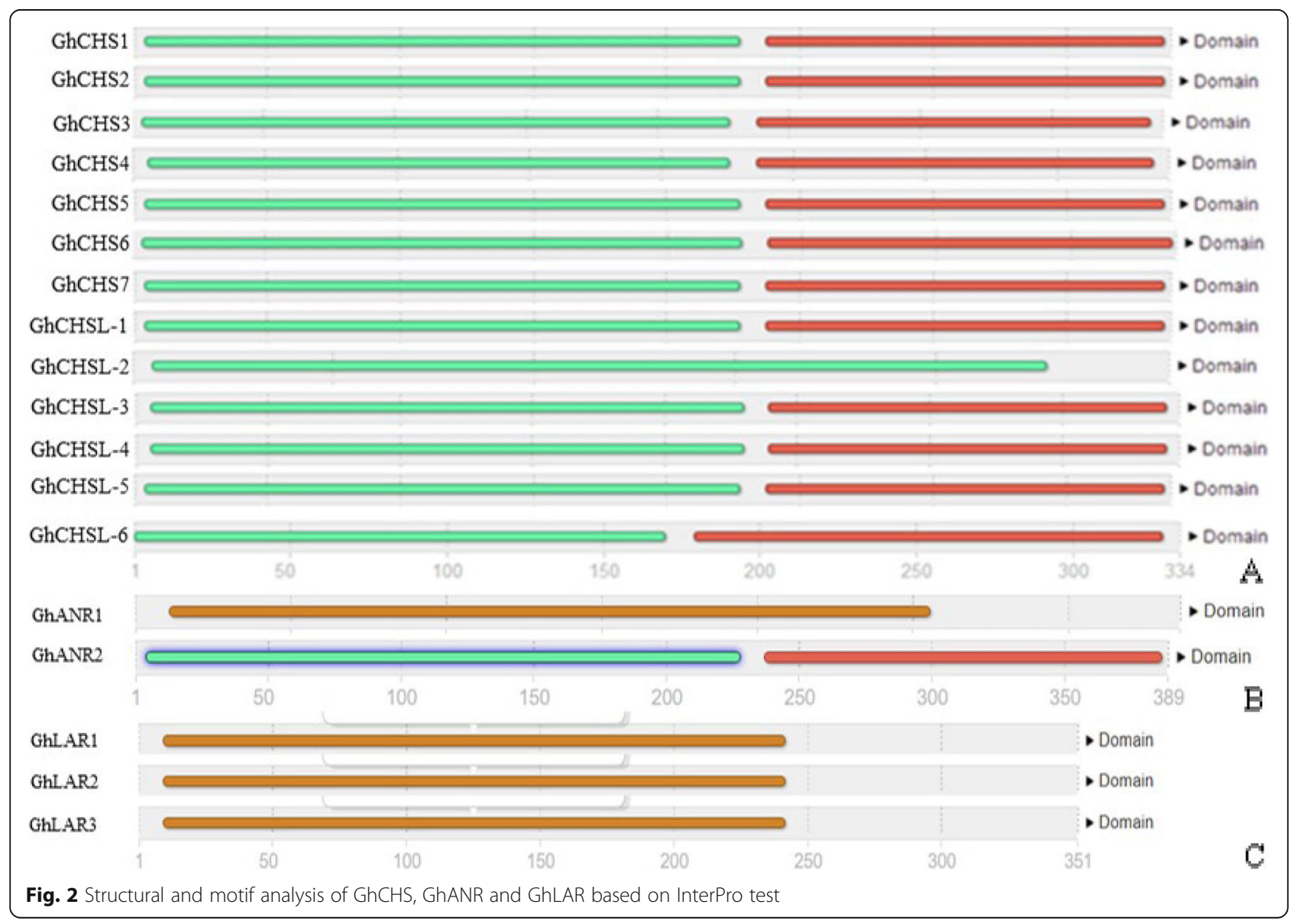




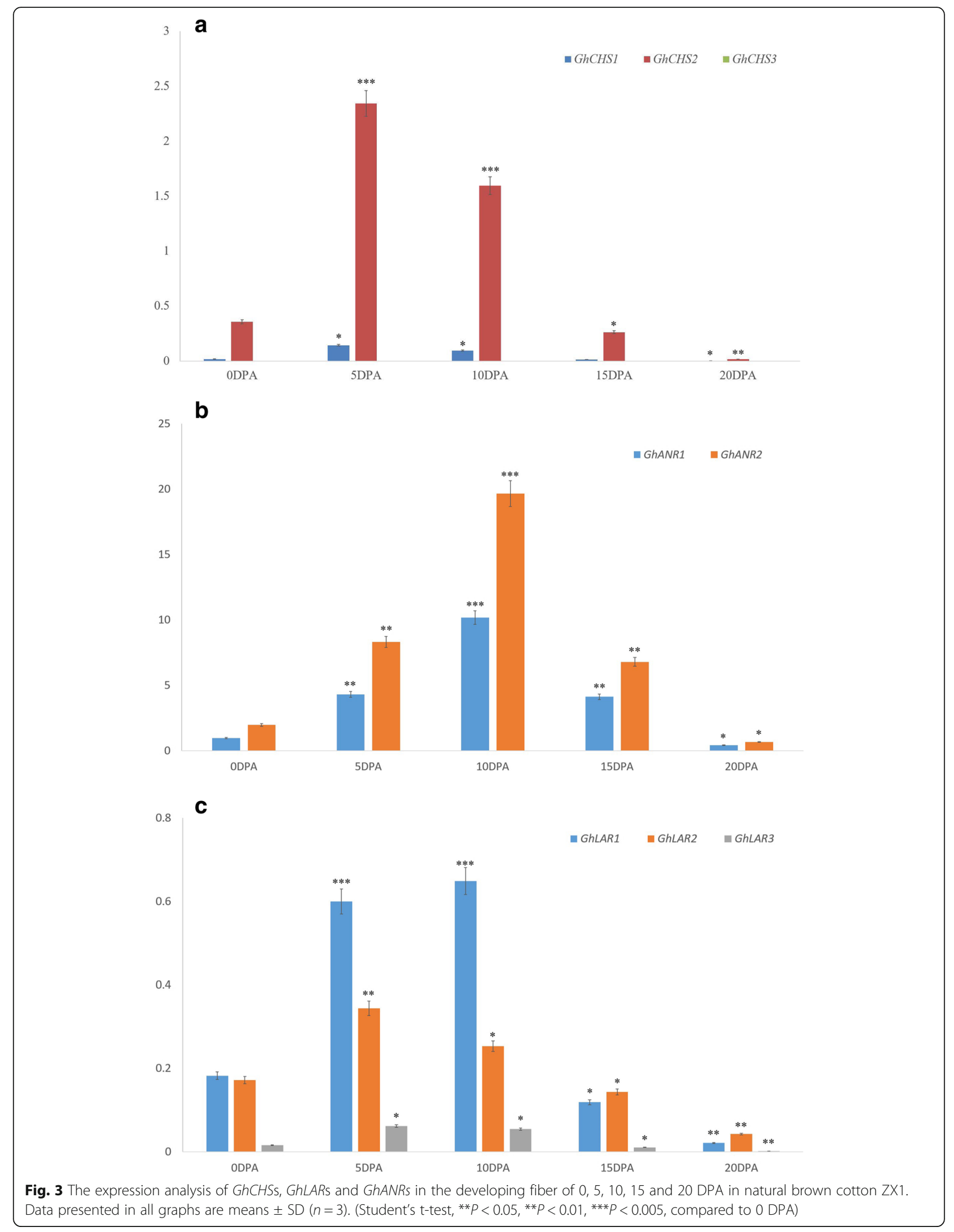




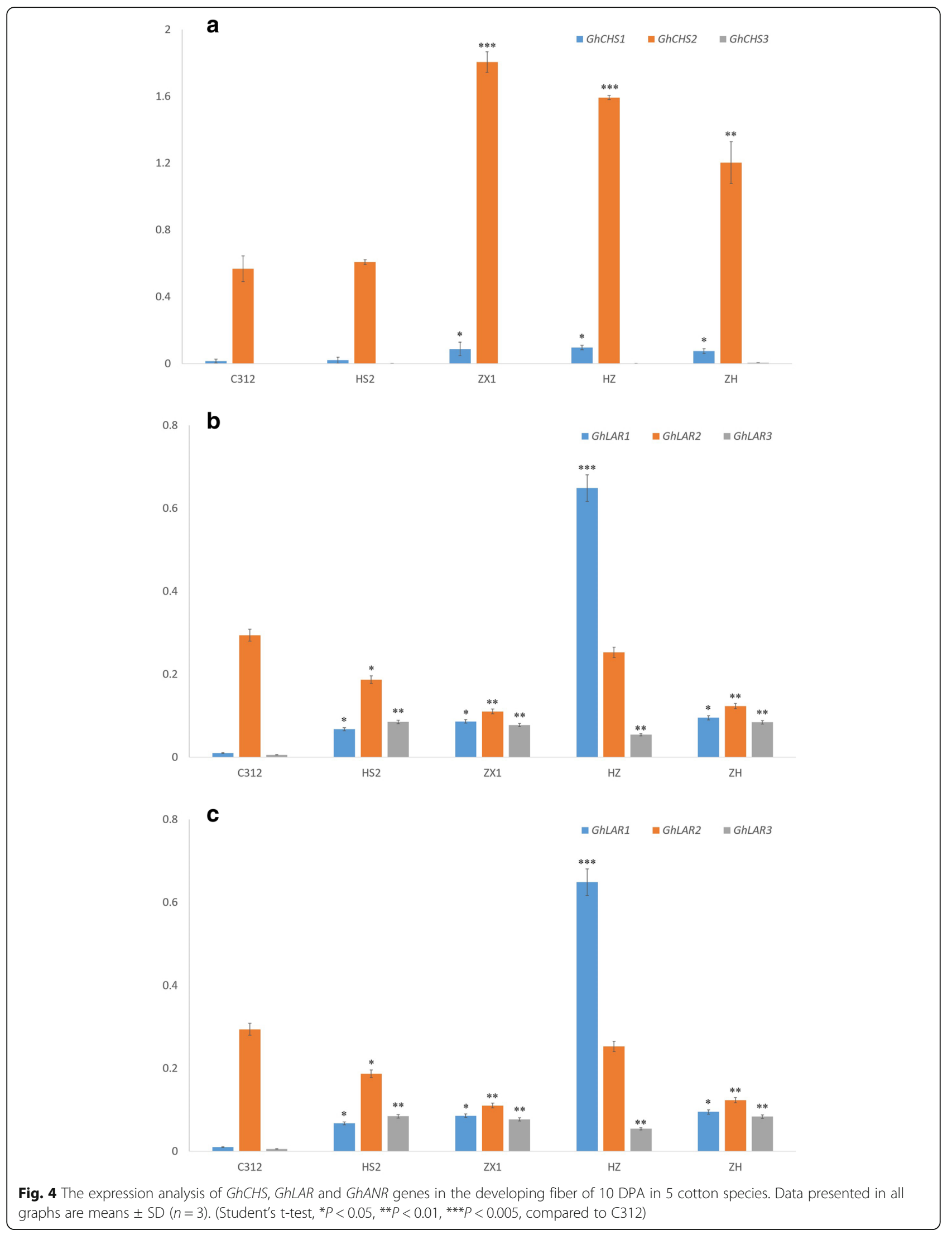


were the highest among the 5 cotton species. The expression of GhANR2 was greatly increased in the dark brown fibers of HZ compared with that in C312, HS2, ZH and ZX1; the transcript level of GhANR1 in ZH lines with light brown was significantly higher than that in C312, HS2, and ZX1 (Fig. 4b). For anthocyanidins transport, the ANR represents the main way for anthocyanidins flowing into fiber cell in natural colored cotton, the expression level of GhANR genes in the developing fiber of the 5 species was extremely higher than that of GhLAR genes and GhCHS genes (Fig. 4). Compared with white cotton fibers, the transcription level of GhANR genes in brown cotton fibers was significantly higher than in white fibers. GhLAR1 gene had the highest expression levels in the deep brown fibers of HZ lines among the 5 cotton species (Fig. 4c), significantly higher than the natural colored cotton $\mathrm{ZX1}, \mathrm{ZH}$ and white fiber cotton C312 and HS2. So the conserved sequences of GhANR1 and GhANR2, GhLAR1 were used to interfere their transcripts.

\section{Phenotypic analysis of transgenic RNAi colored cotton}

The natural colored cotton ZX1 was used to silence the endogenous GhCHS2, GhLAR1 and GhANR genes through CLCrV-based virus-induced gene silencing system. The positive control of transgenic GhPDS-RNAi plant appeared light bleaching symptoms in the leaves, stalks, cotton bolls and cotton fiber, which continued to be expressed in the whole life of cotton. The negative control of transgenic vector-free plants (ZX1 NCK) compared with the wild type only showed the shrinkage of the leaves (Fig. 5). The color of fibers in the GhCHSi, GhANRi and GhLARi were obviously fading in the depth of brown color (Figs. 5, 6). The fiber color in GhANRi plants was distinctly faded with brown color and significantly lighted compared to ZX1 (N CK), the fiber color in GhLARi plants became lighter in the depth of brown color, the cotton fiber color in GhCHSi plants was not significantly different from ZX1, GhPDSi and its N CK (Fig. 6a,b,c). Among the 5 cotton species, the fiber color of $\mathrm{HZ}$ was deeper than the other 4 cotton species, the fiber color of GhANRi HZ plants was obviously lighter than that of WT (HZ) and ZX1 (Fig. 6d). The fiber color in GhANRi $\mathrm{ZH}$ plants also obviously became lighter than WT (ZH) and ZX1 (Fig. 6e). It indicated that GhANR and GhLAR played an important role in the anthocyanin synthesis and the accumulation of pigment in cotton fiber.

\section{Expression analysis of GhCHS, GhANR and GhLAR in RNAi plants}

In the gene-silenced ZX1 plants, the expression levels of GhANR, GhLAR and GhCHS were significantly changed compared to the WT ZX1 and GhPDSi ZX1 plants (Fig. 7).
In the GhCHSi ZX1 plants, the expression level of GhCHS2 in the fibers at 5 DPA and 15 DPA was significantly lower than that of WT ZX1 and GhPDSi ZX1, especially in the developing fiber of 5 DPA (Fig. 7a). The expression level of GhLAR in the GhCHSi ZX1 plants appeared no significant change (Additional file 1: Figure S1A); the expression level of GhANR in the developing fiber of 15 DPA were significantly decreased (Additional file 1: Figure S1B). The brown color of fiber in GhCHSi ZX1 plants was lightly fading (Figs. 5, 6). In the GhANRi ZX1 plants, the GhANR expression level in the developing fibers of 5 DPA, 10 DPA and15DPA were significantly lower than WT ZX1 and GhPDSi ZX1 (Fig. 7b), the expression level of GhCHS in the fibers of 15 DPA increased, but had no significant change in the fibers of 5 DPA and 10DPA (Additional file 1: Figure S1C). The expression level of GhLAR had various changes (Additional file 1: Figure S1D). The color of brown fiber in GhANRi ZX1 plants was strongly fading (Figs. 5, 6). Compared with WT ZX1 and GhPDSi ZX1 plants, the expression level of GhLAR in the fiber of 5 DPA in the GhLARi plants was not all significantly changed, but was markedly increased in the fiber at 10 DPA, sharply decreased in the fibers at 15 DPA (Fig. 7c), the expression level of GhCHS in the fibers of 15 DPA was significantly increased (Additional file 1: Figure S1E), the expression level of GhANR in the fiber of 15 DPA was significantly increased in GhLARi-1 plant (Additional file 1: Figure S1F). The color of brown fiber in GhLARi ZX1 plants was significantly fading (Figs. 5, 6). From the GhANRi and GhLARi ZX1 plants, the suppression of GhANR and GhLAR could upregulate the expression of GhCHS gene (Additional file 1: Figure S1).

\section{The anthocyanin content in plant tissues positively correlated with fiber color}

Natural colored cotton ZX1 was large-area planted with brown fiber, here was used to study the effect of GhANR, GhLAR and GhCHS expression on anthocyanidins accumulation. The content of anthocyanidins of cotton kernel, fiber and seedcoat in WT ZX1 was significantly higher than those in the GhANRi, GhLARi and GhCHSi ZX1 plants (Fig. 8b, c). The contents of anthocyanidins in the RNAi plants were markedly decreased in the cotton kernels, fiber and seedcoat, but the anthocyanidins content was significantly increased in the leaves compared to those in WT ZX1 (Fig. 8a). The contents of anthocyanidins in leaves and cotton kernels of control plants with freearmed vector (N CK) were significantly higher than those in WT (Fig. 8a, c). The content of anthocyanidins in cotton kernels, fiber and seedcoat influenced the fiber color, the fiber color became fading with the anthocyanidins contents reduced in the GhANRi, GhLARi and GhCHSi plants, while the content of anthocyanidins in leaves were increased (Fig. 8b, c). 

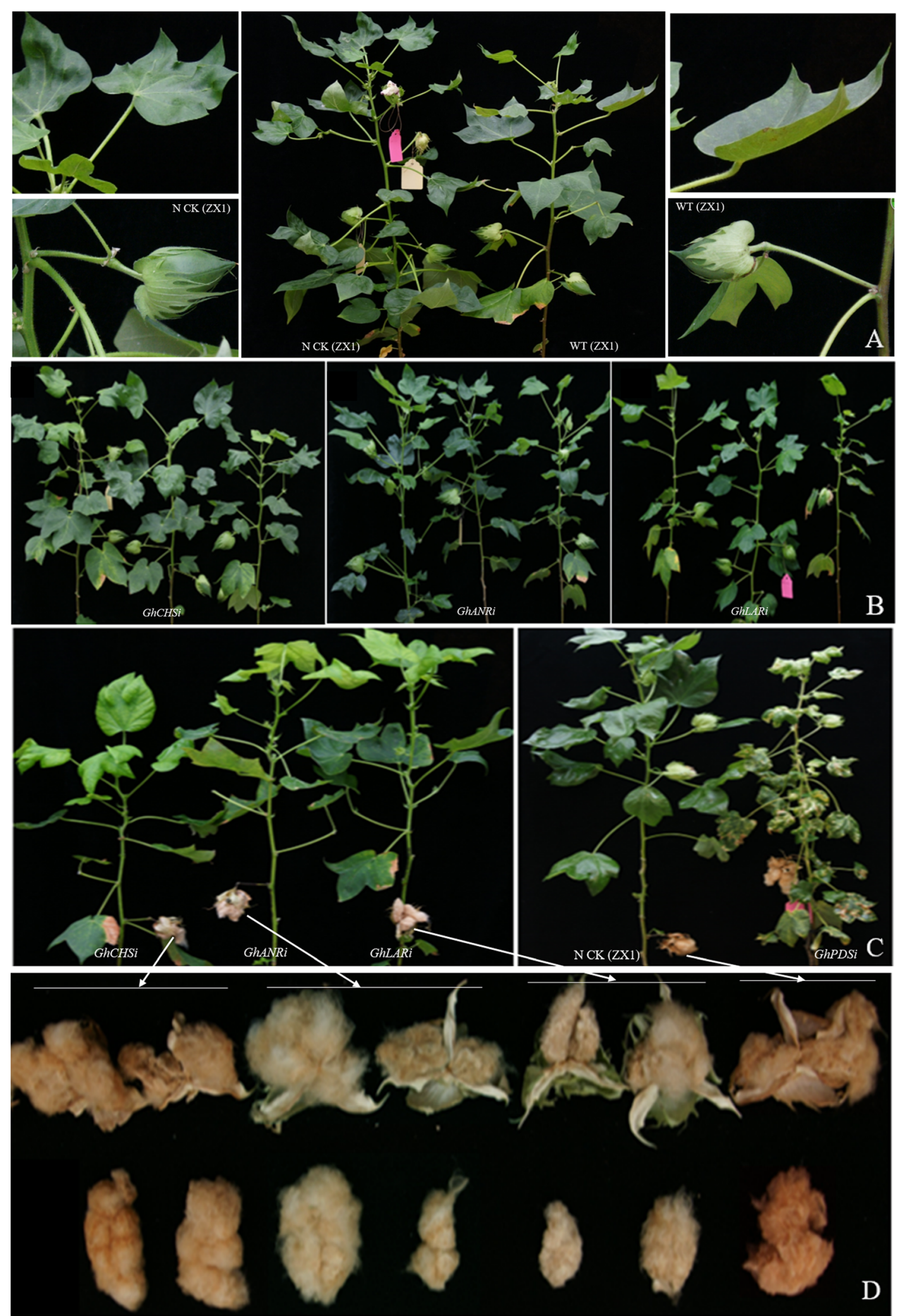

Fig. 5 (See legend on next page.) 
(See figure on previous page.)

Fig. 5 Phenotypic analysis of plant, boll and fiber in GhCHS-RNAi (GhCHSi), GhANR-RNAi (GhANRi), GhANR-RNAi (GhANRi), GhPDS-RNAi (GhPDSi), negative controls ( $N C K$ ) of ZX1 and wild cotton of ZX1 plants (WT ZX1). a: the phenotype of negative controls ZX1 (N CK) and wild cotton ZX1 plants (WT ZX1). b: the transgenic plants of GhCHSi, GhANRi, GhANRi. c: the transgenic plants of GhCHSi, GhANRi, GhANRi with opening bolls. d: the phenotype of boll and fiber of GhCHSi, GhANRi, GhANRi plants

\section{Discussion}

Identification and expression pattern of GhCHS, GhANR and GhLAR

In the genome of G. hirsutum, the 13 GhCHS and GhCHS-like genes in the CHS family, 2 GhANR genes and $3 G h L A R$ genes were scanned, the gene and protein sequences of GhCHS, GhANR and GhLAR were highly conserved, but the genes of GhCHS, GhANR and GhLAR had the expression specificity in cotton plant, GhCHS2 gene was predominantly expressed in colored cotton fibers, GhCHS1 and GhCHS3 expressed weakly in the developing fibers, the other GhCHS and GhCHS-like transcripts in the developing fibers were not measured. GhLAR1, GhLAR2 and GhLAR3 were all expressed in the developing fibers, but differentially expressed in the different cotton species with different colors or colordepth, the 3 GhLAR genes represented the high expressive abundance in the deeply colored fibers of $\mathrm{HZ}$, and perhaps the GhLAR genes could improve the fiber color depth. The 2 GhANR genes were expressed in the developing fibers and obviously increased their transcripts in the colored cotton species, and also showed high expression abundance in the deeply colored fibers of $\mathrm{HZ}$. Among the three types of genes for anthocyanidin biosynthesis and transport, the GhANR genes always maintained high expression level and as well represented the main flow way for anthocyanidins into fiber cell [11] and played the major role for anthocyanidins transport.

\section{The expression levels of GhCHS, GhANR and GhLAR closely related to fiber color}

The 5 cotton species were used to measure the influence of GhCHS, GhANR and GhLAR gene expression on the fiber color formation. The expression levels of GhCHSs and GhANRs, GhLAR1 and GhLAR3 were all predominantly expressed early in developing fibers of colored fibers, especially in the dark brown fiber of HZ (Fig. 4). The expression levels of GhCHS, GhANR and GhLAR positively influenced the color formation of fiber in colored cotton. Therefore, for improving the color of cotton fiber, firstly the GhCHS gene expression would be increased to enhance the anthocyanin biosynthesis, then the GhANR and GhLAR increased their expression for transporting anthocyanidins into fiber cell. In the GhANRi and GhLARi cotton lines, the GhCHS gene was upregulated by the suppression of GhANR $i$ and GhLARi, perhaps in natural colored cotton, the PA formation in the fiber cell could feedback the anthocyanidins biosynthesis, PA formation in fiber cell was mainly resulted from the anthocyanidin transport and accumulation through GhANR and GhLAR. Correspondingly, the suppression of GhCHS in GhCHSi cotton lines, the GhANR was downregulated, perhaps no more anthocyanidins could be transported into fiber cell through GhANR. The content of anthocaynidins in cotton kernels, fiber and seedcoat of GhANRi, GhLARi and GhCHSi plants decreased and increased pattern in leaves could confirm this hypothesis.

\section{The suppression of GhCHS, GhANR and GhLAR had negative effect on fiber color}

The GhANR, GhLAR and GhCHS genes in natural colored cotton ZX1 was silenced, and the fiber color in the transgenic RNAi ZX1 plants was significantly different from the WT and CK. In the transgenic ZX1 plants, the endogenous genes of GhANR, GhLAR and GhCHS were suppressed, especially in the fiber of 5 DPA and 10 DPA (Fig. 7), the fiber color in the transgenic ZX1 plants faded to lighter and even more lighter. The down-regulation levels of the 3 genes emerged as negative correlation with fiber color. In the general phenylpropanoid pathway, chalcone synthase was the first committed enzyme of flavonoid biosynthesis, among the 3 genes, the conserved sequence of GhCHS1, GhCHS2 and GhCHS3 silenced has little significant effect on cotton fiber color. Firstly, it may be multiple members of CHS family in G. hirsutum, although GhCHS2 predominantly expressed early in developing fiber in colored cotton, other members existed functional complementarity after GhCHS2, even GhCHS1 and GhCHS3 suppressed; Secondly, GhCHS genes were in the upstream location of anthocyanidin biosynthesis, suppression of GhCHS had little effect on downstream synthesis and metabolism of anthocyanins. In the early stage of anthocyanidin biosynthetic, $\mathrm{CHS}, \mathrm{CHI}$, and $\mathrm{F} 3 \mathrm{H}$ are the common flavonoid pathway genes (also called early biosynthesis genes, EBGs), and are responsible for the biosynthesis of all downstream flavonoids. The varied expression profile of EBGs was not directly resulted in the change of anthocyanin content in Solanaceous vegetables [43]. The transcript of $\mathrm{SmCHS}$ was significantly increased in black or violet eggplant fruits compared to the light colored mutants of green or white $[44,45]$. In potato tubers, CHS were highly expressed in red and purple tubers and more correlated with anthocyanin content [46-49].

The GhANR and GhLAR worked for anthocyanidins transport in the anthocyanin metabolic pathway, the GhANR played the main role for colored anthocyanidins into fiber cell, the GhLAR worked for transporting leucoanthocyanidin in fiber cell and also could enhance the 


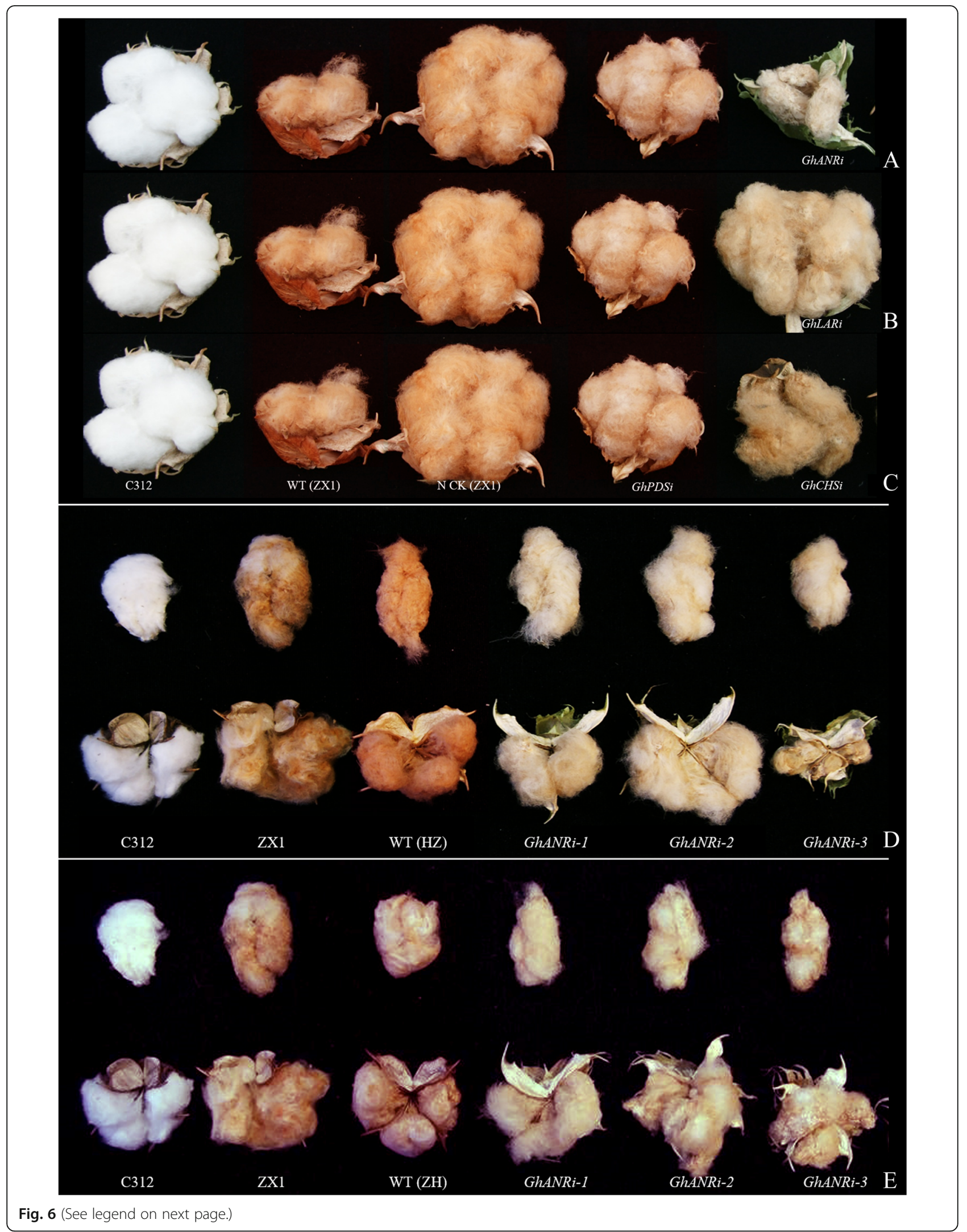


(See figure on previous page.)

Fig. 6 The phenotypic comparison of boll and fiber in GhCHSi, GhANRi, GhANRi, GhPDSi, and different controls of white fiber C312, donor cotton of natural colored cotton (ZX1, HZ and ZH) and C312. a: the phenotypic comparison of fiber in transgenic ZX1 lines of GhCHSi (a), GhANRi (b), GhANRi (c), GhPDSi (positive control ZX1) and different controls of white fiber C312, ZX1, negative control ZX1 (N CK, transgenic ZX1 with vectorfree). $\mathbf{d}$ : the phenotypic comparison of fiber in transgenic $\mathrm{HZ}$ lines of GhCHSi, GhANRi, GhANRi, and different controls (HZ with dark brown fiber). e: the phenotypic comparison of fiber in transgenic ZH lines of GhCHSi, GhANRi, GhANRi, and different controls (ZH with light brown fiber)

fiber color perhaps by polymerization and oxidation to form anthocyanin derivatives [11]. The GhLARs were preferentially expressed in the deep colored fiber of $\mathrm{HZ}$ plant, the fiber color became lighter in the GhLAR suppressed plants.

PAs (also called condensed tannins) are synthesized via a branch of anthocyanin biosynthesis pathway under the catalyzation of LAR and ANR. LAR catalyzes the conversion of leucoanthocyanidin (flavan-3, 4-diol) to catechin, while ANR catalyzes the synthesis of epicatechin from anthocyanidin $[36,50,51]$. The tea CSLAR gene ectopically expressed in tobacco caused the accumulation of higher level of epicatechin than that of catechin, indicating LAR may be response for the biosynthesis of epicatechin [52]. ANRs in grapevine and tea had the epimerase activity and thus could convert anthocyanidin to a mixture of epicatechin and catechin $[52,53]$. The metabolic fluxes were successfully genetically modified in soybean, Arabidopsis, and petunia to redirect the biosynthesis of the isoflavone, the flavonoid, and the anthocyanin, by suppressing the corresponding branchpoint genes [54-56]. The overexpressed Medicago truncatula ANR gene in tobacco reduced anthocyanin pigmentation in the flower and elevated PA levels [51]. Perhaps ANR competes with UF3GT for the substrate anthocyanidin, suppression of ANR genes results in increasing anthocyanin accumulations.

During early seed development, the seed coat was precociously accumulated cyanic pigments in the Arabidopsis ANR (or BAN) knockout mutant [57]. The pigments in seed coat was transitorily accumulated as a transparent testa $(t t)$ phenotype and black pigmentation confined to the raphe of the dried grain [57]. This was different with the phenotype in soybean with red-brown grain by strongly suppressed $A N R$ genes [39]. The underlying mechanistic and metabolite resulted in the different grain phenotypes of different species. In Arabidopsis, the UF3GT (UGT78D2) for anthocyanins in the seedling and the ANR for PAs in the seed coat were regulated reciprocally [58]. In soybean, UF3GT genes including UGT78K1 and UGT78K2, ANR genes including ANR1 and ANR2 were expressed in the seed coat concurrently [39]. The difference of soybean grains phenotype perhaps resulted from $A N R$ gene significant suppression. The presence and absence of UF3GT expression gave the Arabidopsis ANR knockout grain. Thus the red-brown grain phenotype in soybean was resulted from the accumulated of stable anthocyanins.
Two distinct enzymes of LAR and ANR were responsible for catalyzing the last step of the biosynthesis of flavan-3-ol monomers in PA-producing plants [52, 59, 60]. $L A R$ and ANR gene occurs as single gene in Arabidopsis [36], or as multigene families, in grapevine [59] and tea [52]. Analysis of the P. trichocarpa genome revealed three loci encoding LAR and two loci encoding ANR [61, 62], which were likely involved in the catalysis of the last steps of flavan-3-ol biosynthesis in native black poplar from the enzymatic activity and in vitro enzyme assays. ANRs and LARs belong to two distinct classes of enzymes even with the similar evolutionary relationships, DFR was more related to ANRs than LARs [52, 62]. Freely available monomeric catechin was synthesized from the LAR branch and accumulated in black poplar, the concentration of free ANR-dependent epicatechin was very low. The epicatechin might contribute to the extension of PA chains in poplar, grape and Norway spruce $[59,63]$. LARs promoted the biosynthesis of catechin monomers and inhibited their polymerization. The accumulation of catechin monomers and polymers was increased by up-regulating the expression of NtLAR and NtANR s in CsMYB5b transgenic tobacco [64]. So the transport of anthocyanidins through GhANR, GhLAR into fiber cell will be the important link for genetic engineering of colored fiber molecular improvement.

\section{The anthocyanidins content in the fiber directly influenced fiber color}

In the transgenic RNAi cotton plants, the content of anthocyanidins was reduced by suppression of the endogenous GhANR, GhLAR and GhCHS genes, which resulted in the fiber color fading. CHS plays an important role in the phenylalanine metabolic pathway, plant growth and development, such as stress response, plant fertility and plant color [65]. LAR is a key enzyme in the synthetic pathway of plant flavonoids from phenylalanine, which catalyzes the conversion of colorless anthocyanins to catechins [51, 59, 60]. Transcript levels of LAR1 and ANR2 genes were significantly correlated with the contents of catechin and epicatechin to regulate PA synthesis, respectively. Ectopic expression of apple MdLAR1 gene in tobacco suppresses expression of the late genes in anthocyanin biosynthetic pathway, resulting in loss of anthocyanin in flowers [60].

The anthocyanidins content in the fiber and seedcoat of GhLARi plants was higher than GhANRi plants, and the fiber color was also deeper than that of GhANRi plant, 
a

GhCHS relative expression level $\square 5 \mathrm{DPA} \quad \square 10 \mathrm{DPA} \backsim 15 \mathrm{DPA}$

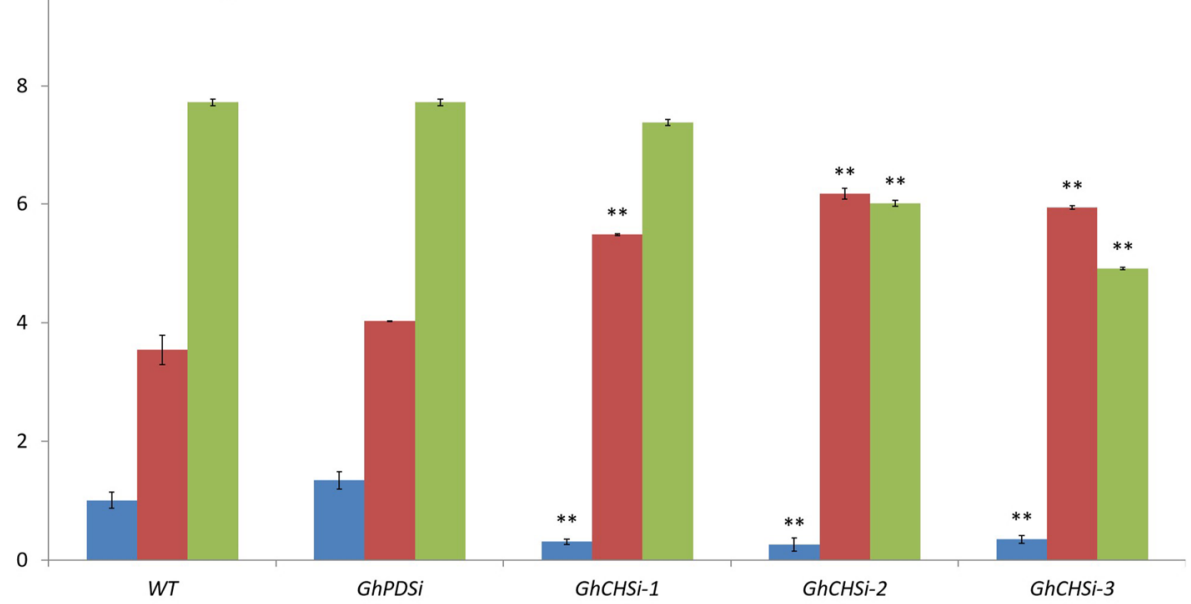

b

$8]$ GhANR relative expression level $\quad$ 5DPA $\because 10 \mathrm{DPA}=15 \mathrm{DPA}$

7

6
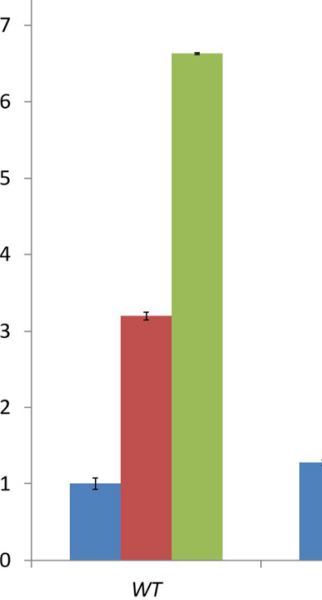

C
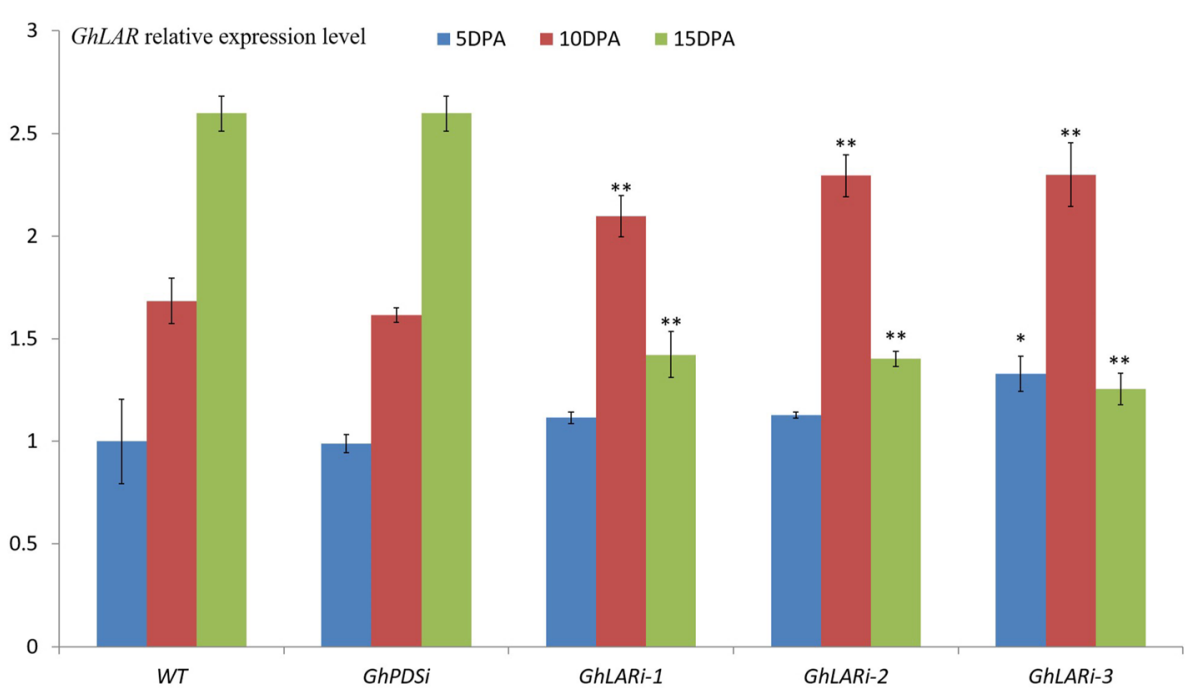

Fig. 7 (See legend on next page.) 
(See figure on previous page.)

Fig. 7 Relative expression levels of GhCHS, GhANR, GhANR in the developing fiber of 5 DPA, 10 DPA and 15 DPA in GhCHSi, GhANRi, GhANRi,

GhPDSi transgenic cotton lines and WT ZX1. a: Relative expression analysis of GhCHS in GhCHSi, GhPDSi transgenic cotton lines and WT. b: Relative expression analysis of GhANR in GhANRi, GhPDSi transgenic cotton lines and WT. c: Relative expression analysis of GhLAR in GhLARi, GhPDSi

transgenic cotton lines and WT. Data presented in all graphs are means \pm SD $(n=3)$, (Student's t-test, ${ }^{*} P<0.05,{ }^{*} P<0.01,{ }^{* * *} P<0.005$, compared to WT)

although LAR transported colorless anthocyanins into fiber cell. From our previous research, the transcription level of GhLAR in the fibers of brown cotton was higher than that in white cotton, during the fiber development, the fiber color of GhLARi plants lightly faded here. Compared with white cotton fibers, the expression level of GhANR in brown cotton fibers was significantly higher. The GhANR was actively expressed in brown cotton fibers and predominantly expressed at $12 \mathrm{DPA}$, when the transcript level of GhANR in brown cotton fibers was higher than that in white cotton fibers with 7-fold [11]. During the fiber development, the transcript level of GhLAR in brown cotton was much lower than that of GhANR, so effect of suppression of GhLAR on the fiber color change was lower than that of GhANR, the suppression of GhANR in ZX1 could cause the fiber color to be significantly lighter. The flavan-3-ols exist in brown and white cotton fibers as the 2, 3-cis form. The most of proanthocyanidins in brown fibers were prodelphidin (PD), while in white cotton fibers, PD content was similar to that of procyanidin (PC). The proanthocyanidin monomeric composition conformed with the expression profiles of proanthocyanidin synthase genes, and ANR played the key role in the proanthocyanidin biosynthesis in brown fibers. The proanthocyanidin synthase genes were expressed at a higher level in brown fibers than in white fibers [11]. The cis-form and trans-form of flavan-3-ols were synthesized in LAR and ANR branches, respectively [11, 36, $51,66]$. Mass spectrometry (MS) analyses revealed that the main PA monomers in brown cotton fibers contained three hydroxyls on the B ring (gallocatechin or epigallocatechin) $[11,21,67]$, PA accumulation in brown fibers starts at an early stage (5 DPA) and peaks at $30 \mathrm{DPA}$, PAs are gradually converted into oxidized derivatives (quinones) in mature brown fibers. Because developing brown fibers do not exhibit distinct coloration until maturation, the condensed quinones maybe directly contribute to brown pigmentation in cotton fibers instead of their PA precursors [11]. Therefore, the three key genes in the anthocyanin metabolic pathways played the very important role in the coloration of cotton fibers, and became the target genes for genetic manipulation to improve cotton fiber color.

\section{Conclusions}

In colored cotton fibers of G. hirsutum, GhCHS2 gene was predominantly expressed in developing colored cotton fibers among 7 GhCHS and 6 GhCHS-like genes and represented $\mathrm{CHS}$ gene in anthocyanin metabolism in colored fibers. 2 GhANR genes and 3 GhLAR genes were highly conserved and homologous, significantly expressed in the developing colored cotton fibers. The GhCHS2, GhANR and GhLAR genes were differentially expressed in the colored cotton fibers with different color depth. The GhCHS, GhANR and GhLAR genes were interfered in colored cottons with different color depth, the expression levels of the three genes were significantly declined, the anthocyanin contents in the RNAi cotton plants were significantly reduced with the declined gene expression, and the fiber color was significantly changed and weaken. The three genes of GhCHS, GhANR and GhLAR played a crucial part in cotton fiber color formation and has important significant to improve natural colored cotton quality through genetic manipulation of the three genes and create new colored cotton germplasm resources by genetic engineering.

\section{Methods \\ Plant materials}

The G. hirsutum L. cv. Coker 312 (C312) and HS2 with white fiber, natural colored cotton ZX1 (Zongxu 1) with brown fiber, $\mathrm{HZ}$ with dark brown fiber and $\mathrm{ZH}$ with lighter brown fiber were used in this study (Fig. 9). The cotton seeds G. hirsutum cv. C312, HS2, ZH and HZ were preserved at the Key Laboratory for Plant Secondary Metabolism and Regulation of Zhejiang Province, Zhejiang Sci-Tech University, Hangzhou, China. C312 was an old commercial variety widely used for genetic transformation and provided by Mid-term National Cotton Germplasm Resource Bank (Institute of Cotton Research, CAAS). ZH, $\mathrm{HZ}$ and $\mathrm{HS} 2$ were new cotton lines cultivated by us. Cotton seeds of ZX1 were kindly provided by Dr. Xiongming $\mathrm{Du}$ (Institute of Cotton Research, CAAS). Seeds were germinated and grown in a greenhouse at $28^{\circ} \mathrm{C}$ with a $14 \mathrm{~h}$ light and $10 \mathrm{~h}$ dark cycle. Seedlings with a 2 nd true leaf emergence were used for agroinfiltration. Infiltrated plants were grown in the greenhouse at $23-25^{\circ} \mathrm{C}$ with a $14 / 10 \mathrm{~h}$ light/dark photoperiod. The cotton plants were cultivated in the field under standard conditions. The samples of cottonseed, fiber and seedcoat were collected at the time of 0 DPA, 5 DPA, 10 DPA, 15 DPA and 20 DPA (days post anthesis) respectively (the fiber and seedcoat at 10 , 15 and 20 DPA were removed from the cotton seed kernel), then put into liquid nitrogen and stored in the $80{ }^{\circ} \mathrm{C}$ ultra-low temperature freezer for RNA extraction. 
a 2

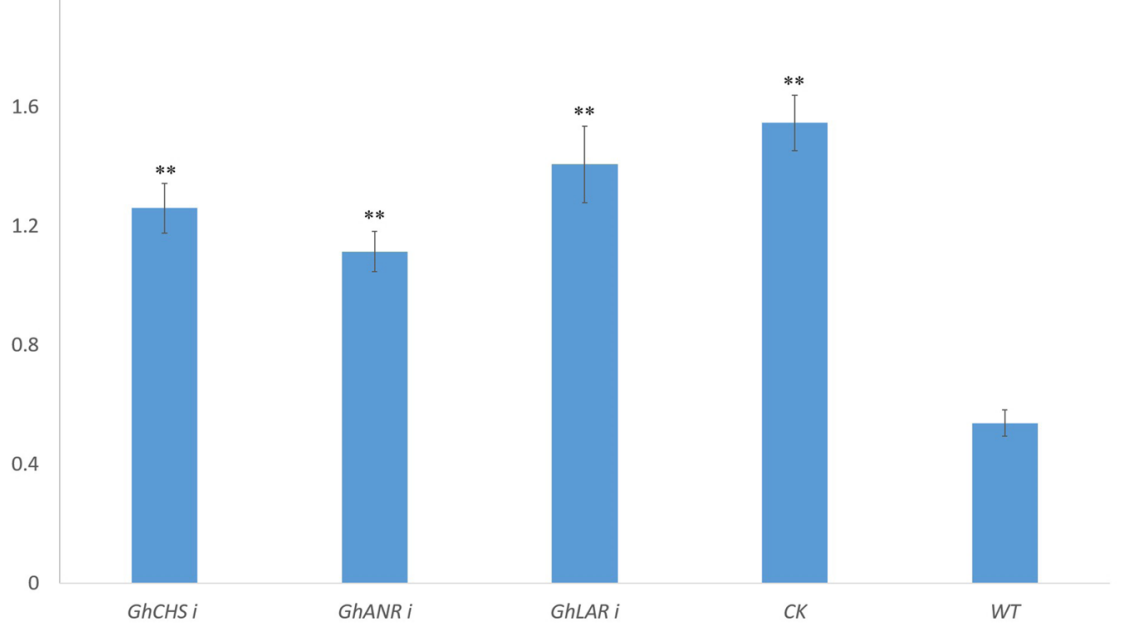

b

0.08

0.06

0.04

0.0

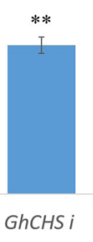

GHANRI

GhLAR i

CK

wT

0

GhCHS i

C
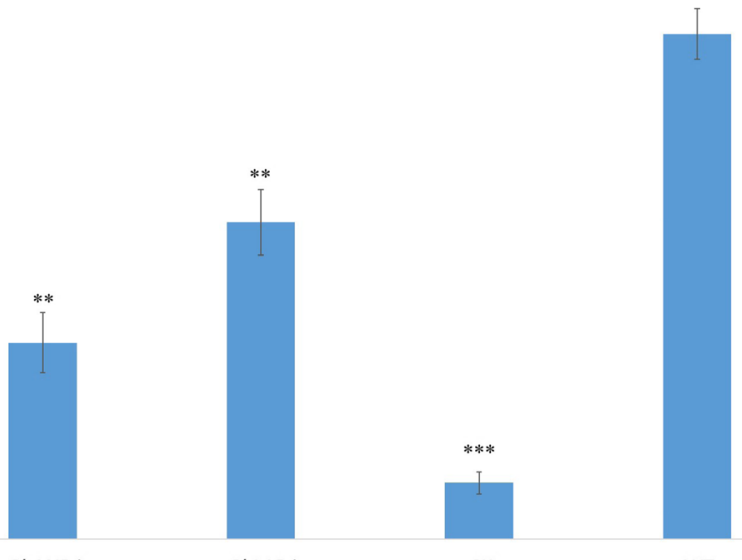

CK

WT
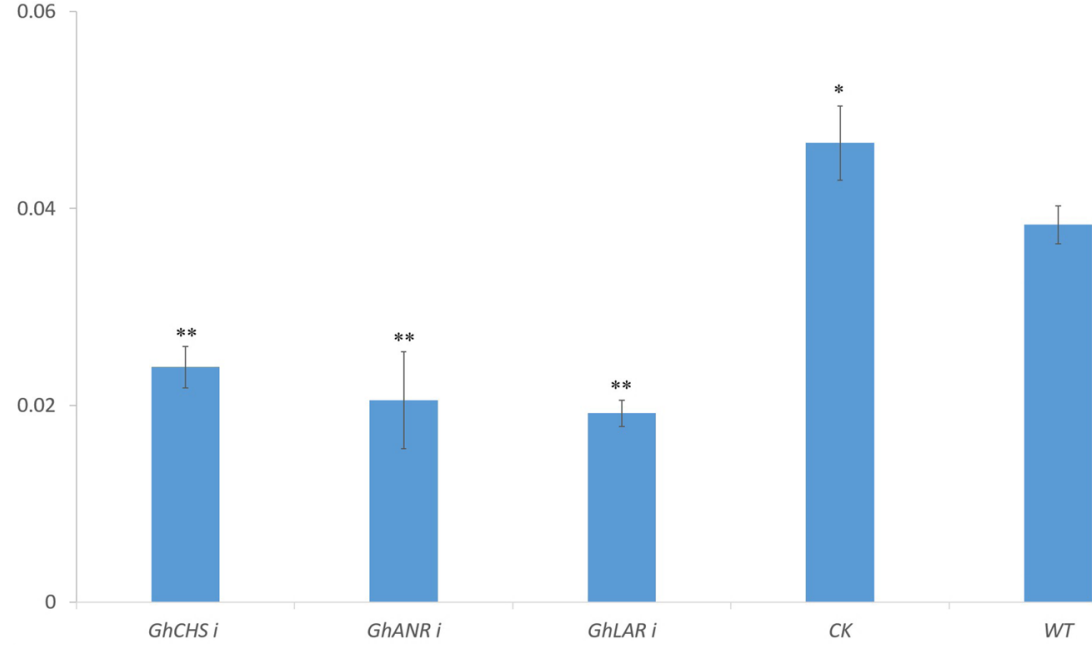

Fig. 8 (See legend on next page.) 
(See figure on previous page.)

Fig. 8 The anthocyanidins content in transgenic plants of GhANRi, GhLARi and GhCHSi, ZX1 (WT) and N CK ZX1. a: The anthocyanidins content in leaves of GhANRi, GhLARi and GhCHSi plants, ZX1 and N CK (Transgenic ZX1 with vector-free); $\mathbf{b}$ : The anthocyanidins content in cotton kernels of GhANRi, GhLARi and GhCHSi plants, WT and N CK; C: The anthocyanidins content in fiber and seedcoat in GhANRi, GhLARi and GhCHSi plants, ZX1 and N CK

\section{Gene cloning and construction of RNAi vectors}

The candidate genes were obtained from the differentially expressed genes in brown cotton and its near isogene line (G. hirsutum) [11]. The GhANR, GhLAR and GhCHS genes were scanned in the cotton genomes (http://www. cottongen.org) for gene accesses and sequences. BioEdit was used for multiple sequence alignment with the amino acid sequences of GhANR1, GhANR2, GhLAR1, GhLAR2, GhLAR3, and GhCHS genes. The characteristics of the genes coded proteins were used TMHMM (http://www. cbs.dtu.dk/services/TMHMM-2.0/) analysis for the transmembrane region of the protein encoded by mRNA. The components, physicochemical properties and isoelectric points of amino acid sequences are analyzed by ProtParam (http://web.expasy.org/ protparam/), respectively.

The new CLCrV-based vector was modified from the CLCrV DNA-A and DNA-B components individually, which were inserted into the pCambia1300 vector to generate pCLCrVA and pCLCrVB, respectively [68]. The fragments of candidate genes were inserted into pCLCrVA to produce pCLCrVA-GhCHS, pCLCrVA-GhANR, pCLCrVAGhLAR for VIGS in cotton plants as described in the previous papers [68-70].

A $400-600 \mathrm{bp}$ fragment of the candidate genes of GhANR2, GhLAR1 and GhCHS2 was amplified as our previous paper [69]. The deficiency of phytoene desaturase gene (PDS) causes loss of chlorophyll and carotenoids, showed the typical photobleaching phenotype, was used as a positive marker to visualize the timing and extent of endogenous gene silencing. The PDS gene fragment was cloned from C312 genomic DNA by PCR to construct vector pCLCrV-GhPDS according to the previous paper [69].

The four vectors were transformed individually into Agrobacterium tumefaciens strain GV3101 [69]. The pCLCrVA-empty was used for a negative control (N CK), the pCLCrV-PDS was used for a positive control (GhPDSi), the pCLCrVA-GhCHS, pCLCrVA-GhANR,
pCLCrVA-GhLAR and pCLCrVB (for target gene silencing) were used. Plants were transformed with pCLCrVPDS and the pCLCrVA-empty vectors as controls. The primers for cloning and detection in the experiment are listed in Additional file 1: Table S1.

Cotton seedlings were grown in a growth chamber at $28^{\circ} \mathrm{C}$ with a $14 \mathrm{~h}$ light and $10 \mathrm{~h}$ dark cycle. Healthy 2 week old seedlings were infiltrated with different Agrobacteria carrying pCLCrVA or one of its derivatives and pCLCrVB. Agrobacteria harboring pCLCrVA or one of its derivatives was mixed with an equal volume of Agrobacteria harboring pCLCrVB. The mixed Agrobacteria solutions were infiltrated into the abaxial side of the cotyledons of the 2-weekold cotton seedlings using syringes without needles. The agroinfiltration was carried out at least three times with at least 30 plants for each vector. DNA was isolated from the leaves of pCLCrV-inoculated cotton plants. The infected plants was detected by PCR using specific primers of CLCrVA F and CLCrVA R [69]. The wild-type C312 and $\mathrm{ZX} 1$ or $\mathrm{HZ}$ or $\mathrm{ZH}$ were used as controls in the experiment. The leaves and developing bolls in transgenic GhCHSi, GhANRi, GhLARi, GhPDSi and CKs plants were respectively collected at $0 \mathrm{DPA}, 5 \mathrm{DPA}, 10 \mathrm{DPA}$ and $15 \mathrm{DPA}$ for measurement of anthocyanin content and gene expression analysis.

\section{Gene expression analysis by quantitative real-time PCR}

Total RNA was isolated from the leaves, the mixture of fiber and seedcoat according to the manufacturer's instructions (RNAprep Pure TIANGEN BIOTECH, China), and treated extensively with RNase-free DNase I. Doublestranded cDNA was synthesized from 200 ng RNA using FastQuant RT kit with gDNase (TIANGEN BIOTECH, China) according to a standard double-stranded cDNA synthesis protocol. Real-time PCR (qRT-PCR) assays were performed using the SYBR FAST qPCR kit (KAPA SYBR ${ }^{\oplus}$, USA) and the qRT-PCR reaction was performed using the

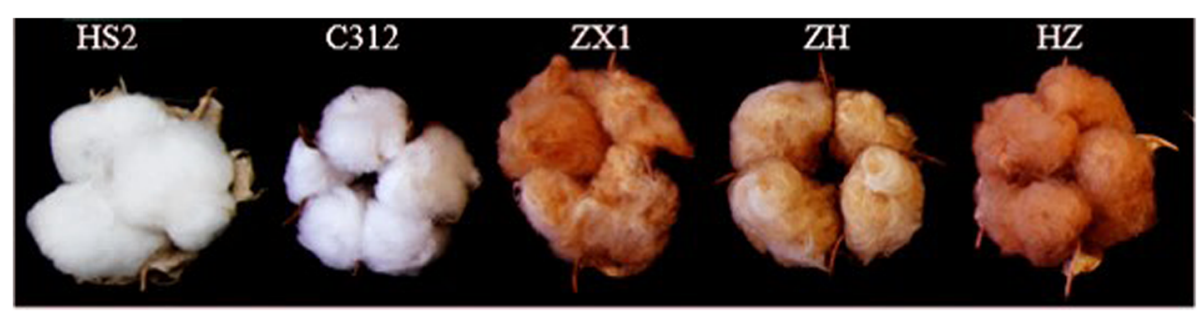

Fig. 9 The phenotype of cotton bolls and fiber in HS2, C312, ZX1, ZH, HZ (G. hirsutum L.) used in the experiments 
ABI QS3 fluorescence quantitative PCR instrument (ABI, USA). The PCR amplification system and program were as described previously [69], three biological replications were performed with independently isolated RNA in all the qRT-PCR assays. Relative gene expression levels were calculated using the $2^{-\Delta \Delta C t}$ method [69]. The expression of GhANR genes, GhLAR genes and GhCHS genes were standardized to the constitutive GhUBQ7 gene expression level (cotton Ubiquitin7 gene, Gen Bank accession number: DQ116441, used as reference gene). The primers are listed in Additional file 1: Table S1.

\section{The analysis of anthocyanin content of transgenic plants} Measurements of anthocyanidin accumulation were performed as described previously [71, 72]. Weighed samples (approx. $100 \mathrm{mg}$ ) in a $1.5 \mathrm{~mL}$ microfuge tubes were harvested into liquid nitrogen to freeze plant tissue. Samples were extracted overnight in $1 \mathrm{ml}$ of $0.5 \%(\mathrm{v} / \mathrm{v}) \mathrm{HCl}$ in methanol, and then violently shaken in vortex for $30 \mathrm{~s}$. The extraction buffers were shaken with $120 \mathrm{rpm}$ in the dark for $1 \mathrm{~h}$. The extraction buffers were centrifuged at $2630 \mathrm{~g}$ for $15 \mathrm{~min}$ at $20^{\circ} \mathrm{C}$. This process was repeated 3 times. The supernatant was assayed spectrophotometrically (UV-2600, Shimadzu, Japan) and anthocyanidin absorbance units $\left(\mathrm{A}_{530}-\mathrm{A}_{657}\right)$ per gram fresh weight were calculated. The blank should be $480 \mathrm{ml}$ Methanol with $0.5 \%(\mathrm{v} / \mathrm{v}) \mathrm{HCl}$ and $320 \mathrm{ml}$ Milli-Q $\mathrm{H}_{2} \mathrm{O}$ for a total of 800 $\mathrm{ml}$. A spectrophotometer was used for the absorbance measurements at 530,620 , and $650 \mathrm{~nm}$. The results were determined based on the following equation: optical density $(\mathrm{OD})=\left(\mathrm{A}_{530}-\mathrm{A}_{620}\right)-\left[0.1 \times\left(\mathrm{A}_{650}-\mathrm{A}_{620}\right)\right][73]$.

\section{Statistical analysis}

All data are presented as mean \pm SD from at least three independent experiments with three replicates each. The statistical significance of the differences was determined using the Student's t-test. Differences between treatments were considered significant when ${ }^{*} P<0.05$, ${ }^{* *} P<$ 0.01 and ${ }^{* * *} P<0.005$ in a two-tailed analysis.

\section{Supplementary information}

Supplementary information accompanies this paper at https://doi.org/10. 1186/s12870-019-2065-7.

Additional file 1: Table S1. Primers used in the experiments. Figure S1. Relative expression levels of GhCHS, GhANR, GhANR in the developing fiber of 5 DPA, 10 DPA and 15 DPA in GhCHSi, GhANRi, GhANRi, GhPDSi transgenic cotton lines and wild cotton ZX1.

\section{Abbreviations}

ANR: Anthocyanidin reductase; CHS: Chalcone synthase; CLCrV: geminivirus Cotton leaf crumple virus; DPA: Days post anthesis; LAR: Leucoanthocyanidin reductase; PA: Proanthocyanidins; PDS: Phytoene desaturase; UF3GT: UDPglycose: flavonoid-3-O-glycosyltransferase

\section{Acknowledgments}

The authors thank Dr. Xiongming Du for providing ZX1 seeds and the helpful discussions.

\section{Authors' contributions}

YS conceived and designed the experiments. JG, LS, JY, HZ, QS, WY, VEN, LZ and LK performed the research and prepared the Figs. 1-7 and Fig. 9. JS participated in data analysis. YS, QL and LK wrote and VEN corrected the article. All authors reviewed and approved the manuscript.

\section{Funding}

This work was supported by the National Key Research and Development Program of China (2018YFD0100401), and General Program of National Natural Science Foundation of China (31671738). The funding agencies had no role in research design, data collection and analysis, or manuscript writing.

Availability of data and materials

All data generated or analyzed during this study are included in this published article.

Ethics approval and consent to participate

Not applicable.

\section{Consent for publication}

Not applicable.

\section{Competing interests}

The authors declare that they have no competing interests.

\section{Author details}

${ }^{1}$ Plant Genomics \& Molecular Improvement of Colored Fiber Lab, Key Laboratory of Plant Secondary Metabolism and Regulation of Zhejiang Province, College of Life Sciences and Medicine, Zhejiang Sci-Tech University, Hangzhou 310016, Zhejiang, China. ${ }^{2}$ College of Agriculture/The Key Laboratory of Oasis Eco-Agriculture, Shihezi University, Shihezi 832000, Xinjiang, China.

Received: 26 June 2019 Accepted: 2 October 2019

Published online: 29 October 2019

\section{References}

1. Hagenbucher S, Olson DM, Ruberson J, Wäckers FL, Romeis J. Resistance mechanisms against arthropod herbivores in cotton and their interactions with natural enemies. Crit Rev Plant Sci. 2013;32:458-82.

2. Efe L, Killi F, Mustafayev SA. An evaluation of eco-friendly natural colored cottons regarding seed cotton yield, yield components and major lint quality traits under conditions of East Mediterranean region of Turkey. Pak J Biol Sci. 2009:12:1346-52.

3. Hua S, Yuan S, Shamsi H, Zhao X, Zhang X, Liu Y, Wen G, Wang X, Zhang H. A comparison of three isolines of cotton differing in fiber color for yield, quality, and photosynthesis. Crop Sci. 2009;49:983-9.

4. Kimmel LB, Day MP. New life for an old fiber: attributes and advantages of natural colored cotton. AATCC Rev. 2001;1:32-6.

5. Gonzalez P, Zaror C. Effect of process modifications on AOX emissions from Kraft pulp bleaching, using chilean pine and eucalyptus. J Clean Prod. 2000; 8:233-41.

6. Sharma A, Thakur W, Shrivastava A, Jain RK, Mathur RM, Gupta R, Kuhad RC. Xylanase and laccase based enzymatic Kraft pulp bleaching reduces adsorbable organic halogen (AOX) in bleach effluents: a pilot scale study. Bioresource Techno. 2014;169:96-102.

7. Ramjaun SN, Yuan R, Wang Z. Liu J degradation of reactive dyes by contact glow discharge electrolysis in the presence of $\mathrm{cl}$ - ions: kinetics and $\mathrm{AOX}$ formation. Electrochim Acta. 2011;58:364-71.

8. $\quad$ Yan $Q$, Wang $Y$, Li Q, Zhang Z, Ding H, Zhang Y, Liu H, Luo M, Liu D, Song W, Liu H, Yao D, Ouyang X, Li Y, Li X, Pei Y, Xiao Y. Upregulation of GhTT2$3 \mathrm{~A}$ in cotton fibers during secondary wall thickening results in brown fibers with improved quality. J Plant Biotechnol. 2018;16:1735-47.

9. Shi YZ, Du XM, Liu GQ, Qiang AD, Zhou ZL, Pan ZE, Sun JL. Genetic analysis of natural colored lint and fuzz of cotton. Cotton Sci. 2002;14:242-8. 
10. Feng $H$, Tian $X$, Liu Y, Li Y, Zhang X, Jones BJ, Sun Y, Sun J. Analysis of flavonoids and the flavonoid structural genes in brown fiber of upland cotton. PLoS One. 2013;8:e58820.

11. Feng $H$, Li Y, Wang S, Zhang L, Liu Y, Xue F, Sun Y, Sun J. Molecular analysis of proanthocyanidins related to pigmentation in brown cotton fibre (Gossypium hirsutum L.). J Exp Bot. 2014;65:5759-69.

12. Tan $Y L$, Zhou XZ. The research status and development trends of natural colored cotton. Progress Text Sci Tech. 2015;2:1-4.

13. Ma M, Hussain M, Memon H, Zhou W. Structure of pigment compositions and radical scavenging activity of natural green-colored cotton fiber. Cellulose. 2016;23:955-63.

14. Bi YW. Performance analysis and development trend of natural colored cotton. Shandong Text Sci Tech. 2017;4:4-7.

15. Du XM, Liu F, Wang KB, Jia YH, Zhou ZL, He SP, Gong WF, Pan ZE, Wang LR, Geng XL, Pang BY. Collection, evaluation and utilization of cotton germplasm. Cotton Sci. 2017;29:51-61.

16. Murthy MS. Never say dye: the story of colored cotton. Resonance. 2001;6: 29-35.

17. Gong W, He S, Tian J, Sun J, Pan Z, Jia Y, Sun G, Du X. Comparison of the transcriptome between two cotton lines of different fiber color and quality. PLoS One. 2014:9:e112966.

18. Hinchliffe DJ, Condon BD, Thyssen G, Naoumkina M, Madison CA, Reynolds M, Delhom CD, Fang DD, Li P, McCarty J. The GhTT2_A07 gene is linked to the brown color and natural flame retardancy phenotypes of Lc1 cotton (Gossypium hirsutum L.) fibres. J Exp Bot. 2016;67:5461-71.

19. Li YJ, Zhang XY, Wang FX, Yang CL, Liu F, Xia GX, Sun J. A comparative proteomic analysis provides insights into pigment biosynthesis in brown color fiber. J Proteome. 2013;78:374-88.

20. Xiao YH, Zhang ZS, Yin MH, Luo M, Li XB, Hou L, Pei Y. Cotton flavonoid structural genes related to the pigmentation in brown fibers. Biochem Biophys Res Commun. 2007;358:73-8.

21. Xiao YH, Yan Q, Ding H, Luo M, Hou L, Zhang M, Yao D, Liu HS, Li X, Zhao J, Pei $Y$. Transcriptome and biochemical analyses revealed a detailed proanthocyanidin biosynthesis pathway in brown cotton fiber. PLoS One. 2014;9:e86344

22. Tohge $T$, Watanabe M, Hoefgen R, Fernie AR. The evolution of phenylpropanoid metabolism in the green lineage. Crit Rev Biochem Mol. 2013:48:123-52.

23. Buer C, Imin N, Djordjevic M. Flavonoids new roles for old molecules. J Integr Plant Biol. 2010;52:98-111.

24. Cheynier V, Comte G, Davies KM, Lattanzio V, Martens S. Plant phenolics: recent advances on their biosynthesis, genetics, and ecophysiology. Plant Physiol Biochem. 2013;72:1-20.

25. Shang $Y$, Venail J, Mackay S, Bailey PC, Schwinn KE, Jameson PE, Martin CR Davies KM. The molecular basis for venation patterning of pigmentation and its effect on pollinator attraction in flowers of antirrhinum. New Phytol. 2011:189:602-15.

26. Tanaka Y, Ohmiya A. Seeing is believing: engineering anthocyanin and carotenoid biosynthetic pathways. Curr Opin Biotechnol. 2008;19:190-7.

27. Smeriglio A, Barreca D, Bellocco E, Trombetta D. Chemistry, pharmacology and health benefits of anthocyanins. Phytother Res. 2016:30(8):1265-86.

28. Kong JM, Chia LS, Goh NK, Chia TF, Brouillard R. Analysis and biological activities of anthocyanins. Phytochem. 2003;64:923-33.

29. Zhang Y, Butelli E, Martin C. Engineering anthocyanin biosynthesis in plants. Curr Opin Plant Biol. 2014;19:81-90.

30. Feild TS, Lee DW, Holbrook NM. Why leaves turn red in autumn. The role of anthocyanins in senescing leaves of red-osier dogwood. Plant Physiol. 2001; 127:566-74.

31. Gould KS, Mckelvie J, Markham KR. Do anthocyanins function as antioxidants in leaves? Imaging of $\mathrm{H} 2 \mathrm{O} 2$ in red and green leaves after mechanical injury. Plant Cell Environ. 2010;25:1261-9.

32. Li J, Ou-Lee TM, Raba R, Amundson RG, Last RL. Arabidopsis flavonoid mutants are hypersensitive to UV-B irradiation. Plant Cell. 1993;5:171-9.

33. Olsen KM, Slimestad R, Lea US, Brede C, Løvdal T, Ruoff P, Verheul M, Lillo C. Temperature and nitrogen effects on regulators and products of the flavonoid pathway: experimental and kinetic model studies. Plant Cell Environ. 2010;32:286-99.

34. Rubin G, Tohge T, Matsuda F, Saito K Scheible W. Members of the LBD family of transcription factors repress anthocyanin synthesis and affect additional nitrogen responses in Arabidopsis. Plant Cell. 2009; 21:3567-84.
35. Koes R, Verweij W, Quattrocchio F. Flavonoids: a colorful model for the regulation and evolution of biochemical pathways. Trends Plant Sci. 2005; 10:236-42.

36. Xie DY, Sharma SB, Dixon RA. Anthocyanidin reductases from Medicago truncatula and Arabidopsis thaliana. Arch Biochem Biophys. 2004;422:91-102.

37. Liu C, Wang X, Shulaev V, Dixon RA. A role for leucoanthocyanidin reductase in the extension of proanthocyanidins. Nat Plants. 2016;2:16182.

38. Nishihara M, Nakatsuka T. Genetic engineering of flavonoid pigments to modify flower color in floricultural plants. Biotechnol Lett. 2011;33:433-41.

39. Kovinich N, Saleem A, Rintoul TL, Brown DC, Arnason JT, Miki B. Coloring genetically modified soybean grains with anthocyanins by suppression of the proanthocyanidin genes ANR1 and ANR2. Transgenic Res. 2012;21:757-71.

40. McCallum JA, Walker JR. Proanthocyanidins in wheat bran. Cereal Chem 1990;67:282-5.

41. Naczk M, Nichols T, Pink D, Sosulski F. Condensed tannins in canola hulls. J Agric Food Chem. 1994;42:2196-200.

42. Venglat $\mathrm{P}$, Xiang D, Qiu S, Stone SL, Tibiche C, Cram D, Alting-Mees M, Nowak J, Cloutier S, Deyholos M, Bekkaoui F, Sharpe A, Wang E, Rowland G, Selvaraj G, Datla R. Gene expression analysis of flax seed development. BMC Plant Biol. 2011;11:1-15.

43. Liu Y, Tikunov Y, Schouten RE, Marcelis L, Visser R, Bovy A. Anthocyanin biosynthesis and degradation mechanisms in solanaceous vegetables: a review. Front Chem. 2018:6:52.

44. Stommel JR, Dumm JM. Coordinated regulation of biosynthetic and regulatory genes coincides with anthocyanin accumulation in developing eggplant fruit. J Am Soc Hortic Sci. 2015;140:129-35.

45. Gisbert C, Dumm JM, Prohens J, Vilanova S, Stommel JR. A spontaneous eggplant (Solanum melongena L.) color mutant conditions anthocyanin-free fruit pigmentation. Hortsci. 2016;51:793-8.

46. André CM, Schafleitner R, Legay S, Lefèvre I, Aliaga CA, Nomberto G, Hoffmann L, Hausman JF, Larondelle Y, Evers D. Gene expression changes related to the production of phenolic compounds in potato tubers grown under drought stress. Phytochem. 2009;70:1107-16.

47. Jung CS, Griffiths HM, De Jong DM, Cheng S, Bodis M, Kim TS, De Jong WS. The potato developer (D) locus encodes an R2R3 MYB transcription factor that regulates expression of multiple anthocyanin structural genes in tuber skin. Theor Appl Gene. 2009;120:45-57.

48. Payyavula RS, Singh RK, Navarre DA. Transcription factors, sucrose, and sucrose metabolic genes interact to regulate potato phenylpropanoid metabolism. J Exp Bot. 2013:64:5115-31.

49. Liu Y, Lin-Wang K, Deng C, Warran B, Wang L, Yu B, Yang H, Wang J, Espley RV, Zhang J, Wang D, Allan AC. Comparative transcriptome analysis of white and purple potato to identify genes involved in anthocyanin biosynthesis. PLoS One. 2015:10:e0129148.

50. Tanner GJ, Francki KT, Abrahams S, Watson JM, Larkin PJ, Ashton AR. Proanthocyanidin biosynthesis in plants. Purification of legume leucoanthocyanidin reductase and molecular cloning of its cDNA. J Biol Chem. 2003;278:31647-56.

51. Xie DY, Sharma SB, Paiva NL, Ferreira D, Dixon RA. Role of anthocyanidin reductase, encoded by BANYULS in plant flavonoid biosynthesis. Science. 2003:299:396-9.

52. Pang Y, Abeysinghe IS, He J, He XZ, Huhman D, Mewan KM, Sumner LW, Yun J, Dixon RA. Functional characterization of proanthocyanidin pathway enzymes from tea and their application for metabolic engineering. Plant Physiol. 2013;161:1103-16.

53. Gargouri M, Chaudière J, Manigand C, Maugé C, Bathany K, Schmitter JM, Gallois B. The epimerase activity of anthocyanidin reductase from Vitis vinifera and its regiospecific hydride transfers. Biol Chem. 2010;391:219-27.

54. Yu O, Shi J, Hession AO, Maxwell CA, McGonigle B, Odell JT. Metabolic engineering to increase isoflavone biosynthesis in soybean seed. Phytochem. 2003;63:753-63.

55. Besseau S, Hoffmann L, Geoffroy P, Lapierre C, Pollet B, Legrand M. Flavonoid accumulation in Arabidopsis repressed in lignin synthesis affects auxin transport and plant growth. Plant Cell. 2007:19:148-62.

56. Nakatsuka T, Abe Y, Kakizaki Y, Yamamura S, Nishihara M. Production of redflowered plants by genetic engineering of multiple flavonoid biosynthetic genes. Plant Cell Rep. 2007;26:1951-9.

57. Albert S, Delseny M, Devic M. BANYULS, a novel negative regulator of flavonoid biosynthesis in the Arabidopsis seed coat. Plant J. 1997;11:289-99.

58. Lee Y, Yoon H, Paik YS, Liu JR, Chung WI, Choi G. Reciprocal regulation of Arabidopsis UGT78D2 and BANYULS is critical for regulation of the 
metabolic flux of anthocyanidins to condensed tannins in developing seed coats. J Plant Biol. 2005;48:356-70.

59. Bogs J, Downey MO, Harvey JS, Ashton AR, Tanner GJ, Robinson SP. Proanthocyanidin synthesis and expression of genes encoding leucoanthocyanidin reductase and anthocyanidin reductase in developing grape berries and grapevine leaves. Plant Physiol. 2005;139:652-63.

60. Liao L, Vimolmangkang S, Wei G, Zhou H, Korban SS, Han Y. Molecular characterization of genes encoding leucoanthocyanidin reductase involved in proanthocyanidin biosynthesis in apple. Front Plant Sci. 2015;6:243.

61. Yuan L, Wang L, Han Z, Jiang Y, Zhao L, Liu H, Yang L, Luo K. Molecular cloning and characterization of PtrLAR3, a gene encoding

leucoanthocyanidin reductase from Populus trichocarpa, and its constitutive expression enhances fungal resistance in transgenic plants. J Exp Bot. 2012; 63:2513-24.

62. Wang Y, Chun OK, Song WO. Plasma and dietary antioxidant status as cardiovascular disease risk factors: a review of human studies. Nutrients. 2013:5:2969-3004.

63. Hammerbacher A, Paetz C, Wright LP, Fischer TC, Bohlmann J, Davis AJ, Fenning TM, Gershenzon J, Schmidt A. Flavan-3-ols in Norway spruce: biosynthesis, accumulation, and function in response to attack by the bark beetle-associated fungus Ceratocystis polonica. Plant Physiol. 2014;164: 2107-22.

64. Wang $P Q$, Zhang $L$, Jiang $X L$, Dai $X L$, Xu LJ, Li T, Xing DW, Li YZ, Li MZ, Gao $L P, X i a T$. Evolutionary and functional characterization of leucoanthocyanidin reductases from Camellia sinensis. Planta. 2018;247:139-54.

65. Koes RE, Quattrocchio F, Mol JN. The flavonoid biosynthetic pathway in plants: function and evolution. Bioessays. 1994;16:123-32.

66. Takos AM, Ubi BE, Robinson SP, Walker AR. Condensed tannin biosynthesis genes are regulated separately from other flavonoid biosynthesis genes in apple fruit skin. Plant Sci. 2006;170:487-99.

67. Tuttle JR, Idris AM, Brown JK, Haigler CH, Robertson D. Geminivirusmediated gene silencing from Cotton Leaf Crumple Virus is enhanced by low temperature in cotton. Plant Physiol. 2008;148:41-50.

68. Gu Z, Huang C, Li F, Zhou X. A versatile system for functional analysis of genes and micrornas in cotton. Plant Biotechnol J. 2014;12:638-49.

69. Fu WF, Shen Y, Hao J, Wu JY, Ke LP, Wu CY, Huang K, Luo BL, Xu MF, Cheng XF, Zhou XP, Sun J, Xing CZ, Sun YQ. Acyl-CoA N-acyltransferase influences fertility by regulating lipid metabolism and jasmonic acid biogenesis in cotton. Sci Rep. 2015:5:11790.

70. Lu R, Martin-Hernandez AM, Peart JR, Malcuit I, Baulcombe DC. Virusinduced gene silencing in plants. Methods. 2004;30:296-303.

71. Jeong SW, Das PK, Jeoung SC, Song JY, Lee HK, Kim YK, Kim WJ, Park YI, Yoo SD, Choi SB, Choi G, Park YI. Ethylene suppression of sugar-induced anthocyanin pigmentation in Arabidopsis. Plant Physiol. 2010;154(3):1514-31.

72. Wade HK, Sohal AK, Jenkins GI. Arabidopsis ICXI is a negative regulator of several pathways regulating flavonoid biosynthesis genes. Plant Physiol. 2003;131(2):707-15.

73. An JP, Qu FJ, Yao JF, Wang XN, You CX, Wang XF, Hao YJ. The bZIP transcription factor MdHY5 regulates anthocyanin accumulation and nitrate assimilation in apple. Horticulture Research. 2017;4:17023.

\section{Publisher's Note}

Springer Nature remains neutral with regard to jurisdictional claims in published maps and institutional affiliations.

Ready to submit your research? Choose BMC and benefit from:
- fast, convenient online submission
- thorough peer review by experienced researchers in your field
- rapid publication on acceptance
- support for research data, including large and complex data types
- gold Open Access which fosters wider collaboration and increased citations
- maximum visibility for your research: over 100M website views per year
At BMC, research is always in progress.
Learn more biomedcentral.com/submissions

